\begin{tabular}{|c|c|c|}
\hline $\begin{array}{l}\text { PKS } \\
\text { PUBLIC } \\
\text { KNOOLEDGE } \\
\text { PROJECT }\end{array}$ & $\begin{array}{c}\text { REVISTA DE GEOGRAFIA } \\
\text { (RECIFE) } \\
\text { http://www.revista.uffe.br/revistageografia }\end{array}$ & $\begin{array}{l}\text { OJS } \\
\frac{\text { OPEN }}{\text { JOUNAL }} \\
\text { SYSTEMS }\end{array}$ \\
\hline
\end{tabular}

\title{
INTENSIDADE DE ENTRELAÇAMENTO, SINUOSIDADE E DECLIVIDADE EM SETORES DA BACIA HIDROGRÁFICA DO RIO MUNDAÚ (AL-PE)
}

\author{
Genisson Panta ${ }^{1}$, Kleython de Araújo Monteiro ${ }^{2}$ \\ ${ }^{1}$ Instituto de Geografia, Desenvolvimento e Meio Ambiente (UFAL). Email: genissongeo@gmail.com \\ ${ }^{2}$ Professor Adjunto do Instituto de Geografia, Desenvolvimento e Meio Ambiente (UFAL). Email: \\ geokleython@gmail.com
}

Artigo recebido em 05/12/2017 e aceito em 09/03/2018

\begin{abstract}
RESUMO
Os rios entrelaçados são caracterizados por apresentarem baixa sinuosidade, alta variação da vazão, predominância de carga de fundo e um canal que se divide e se reúne em um complexo arranjo geomorfológico. Atualmente existe reconhecida dificuldade em se quantificar a intensidade de entrelaçamento porque as formas que lhe dão origem possuem geralmente baixo tempo de permanência dentro do sistema fluvial. Utilizaram-se imagens disponibilizadas pelo software Google Eath Pro dos meses de novembro e dezembro de 2015 e 2016 para se quantificar a intensidade do entrelaçamento em setores do rio principal da Bacia Hidrográfica do Mundaú, nordeste brasileiro. Concomitantemente mediu-se a sinuosidade do canal e a declividade nos segmentos entrelaçados. Esta pesquisa permitiu observar que existe predominância de baixa sinuosidade nos trechos contemplados pela análise, bem como baixa frequência de altos valores de intensidade de entrelaçamento e declividade baixa ao longo dos trechos.
\end{abstract}

Palavras-chaves: Rios Entrelaçados; Morfometria; Rios Tropicais.

\section{BRAIDING INTENSITY, SINUOSITY AND SLOPE IN SECTORS OF THE MUNDAÚ RIVER BASIN (AL-PE)}

\begin{abstract}
The braided rivers are characterized by low sinuosity, high flow variation, predominance of bed load and a channel which divides itself and rejoin in a complex geomorphological arrangement. Currently, there is a difficulty in quantifying the intensity of braid because the forms have a short residence time inside fluvial system. We used images provided by the Google Eath Pro software of november and december of 2015 and 2016 to quantify the braiding intensity in sectors of the main channel of the Mundaú River Basin, northeastern Brazil. At the same time, the sinuosity of the channel and the slope in the braided segments were measured. This research allowed to observe that there is predominance of low sinuosity in the sections contemplated by analysis, as well as low frequency of high values of braiding intensity and low slope along the sectors.
\end{abstract}

Keywords: Braided Rivers; Morphometry; Tropical Rivers. 


\section{INTRODUÇÃO}

Tradicionalmente, o padrão de canal tem sido delineado a partir da morfologia em planta que determinado rio apresenta e classificado de acordo com a proposta dos cientistas americanos Luna B. Leopold e Markley G. Wolman, como retilíneo (straight), meandrante (meandring) e entrelaçado (braided), podendo haver gradação e coexistência destes padrões dentro de uma mesma rede de drenagem (LEOPOLD \& WOLMAN, 1957). A morfologia apresentada por determinado rio expressa, em última análise, o estado de quase equilíbrio entre as variáveis hierárquicas do sistema, como o volume e o tipo de carga sedimentar, a magnitude e frequência das descargas, a pendente do canal, a largura, a profundidade, entre outras (BIGARELLA et al, 2003).

O padrão do canal pode variar, dentro de uma mesma bacia hidrográfica, tanto espacialmente quanto temporalmente. Os rios entrelaçados podem ser encontrados em uma ampla gama de ambientes: clima semiárido com vegetação espaçada e precipitações concentradas em determinadas épocas do ano, regiões úmidas com alta densidade de vegetação ripária e precipitação abundante, dentre outros. Tendo em vista essa diversidade de situações e o fato de ainda não existirem modelos tridimensionais para classificação, atualmente não existe consenso entre os especialistas sobre a classificação dos padrões de canais (BIGARELLA et al, 2003; STEVAUX \& LATRUBESSE, 2017).

Os rios entrelaçados são caracterizados por apresentarem um canal que se separa e se junta, segmentados por barras e ilhas arenosas e cascalhosas, com predominância de carga de fundo, alta variação da descarga, elevada relação largura/profundidade (geralmente maior que 40), baixa sinuosidade, margens erodíveis, descarga variável e gradiente pronunciado. Esses elementos associam-se e podem apresentar maior ou menor controle na morfologia do canal, como ressalta Stevaux e Labrubesse (2017).

O primeiro cientista a elaborar uma formulação matemática objetivando medir o grau de entrelaçado de um canal foi James C. Brice, na década de 1960. Este autor propunha que o dobro do somatório do comprimento das barras e/ou ilhas, em determinado trecho, dividido pelo comprimento do setor medido ao meio do canal, seria um indicativo relevante do grau de entrelaçamento de determinado rio. Segundo Fried \& Sinha (1993), várias modificações foram introduzidas no cálculo do índice de entrelaçamento, como os autores que levam em consideração a sinuosidade e o comprimento do talvegue do canal, como o parâmetro de 
entrelaçamento de Brian R. Rust, em 1978, e posteriormente a razão canal-barra de Keitch S. Richards, em 1982.

Vários autores reconhecem que se comparado a outras tipologias fluviais, como os rios meandriformes, os rios entrelaçados contam normalmente com menos estudos e são relativamente poucos os trabalhos que tratam especificamente das relações morfométricas de sua morfologia, tendo em vista a dificuldade da mensuração do entrelaçamento, devido sua mobilidade (CRISTOFOLETTI, 1981; SMITH, 2006). Assim, torna-se imprescindível realizar esforços científicos no sentido de contribuir com o entendimento e quantificação da morfologia destes rios na zona intertropical (LATRUBESSE; STEVAUX; SINHA, 2005), em diversas escalas espaciais e temporais.

Este estudo buscou, por meio de imagens de satélite disponibilizadas pelo software Google Earth Pro, dos meses de novembro e dezembro de 2015 e 2016, período de estiagem na bacia, quantificar o entrelaçamento de setores do rio principal da bacia do Mundaú, nordeste brasileiro, através da formulação de James C. Brice (1964). Ao todo foram mensurados 25 setores de 1,5 km cada. Aplicou-se também o parâmetro de sinuosidade nos trechos estudados, através do parâmetro estabelecido por Fried e Sinha (1993) e o cálculo de declividade utilizado também por Tavares et al (2009).

\section{MATERIAL E MÉTODOS}

\section{Área de estudo}

A área de estudo compreende o canal principal da Bacia Hidrográfica do Mundaú (BHM) em sua totalidade, aproximadamente $200 \mathrm{~km}$ de extensão. Entende-se como canal principal o rio mais extenso do exutório até a cabeceira (SHREVE apud CHRISTOFOLETTI, 1980). A BHM drena parte de Pernambuco e Alagoas e tem área estimada em $4.126 \mathrm{~km}^{2}$, localizada na Região Hidrográfica Atlântico Nordeste Oriental. Seu alto curso localiza-se a sudeste do Planalto da Borborema, um dos principais divisores de águas do nordeste brasileiro (MAIA \& BEZERRA, 2011).

A geomorfologia da bacia é compartimentada em três grandes unidades: Planalto da Borborema, Depressão Periférica e Tabuleiros Costeiros estruturados em sedimentos miocênicos, bem como possui planícies aluviais preenchidas por sedimentos quaternários (GOMES et al, 2016). O clima da bacia é classificado como Tropical, com precipitação média anual acumulada de $900 \mathrm{~mm}$, mas devido à sua extensão possui uma grande amplitude, 
podendo atingir volume superior à $1800 \mathrm{~mm}$ em seu baixo curso. Dentro dos limites da BHM encontra-se ampla diversidade pedológica com ocorrência de argissolos, latossolos, luvissolos, neossolos litólicos, neossolos flúvicos, gleissolos, dentre outros. O uso do solo na bacia é marcado por atividades agropecuárias e áreas urbanas $(75,68 \%)$ e apenas $22,76 \%$ da BHM possui cobertura vegetal arbórea ou arbustiva. Sua população total é de 441.000 habitantes, sendo 220 mil em Pernambuco e 221 mil em Alagoas (GOMES op cit.). O rio Mundaú desemboca na laguna homônima, em Alagoas, no município de Maceió (MONTE et $a l, 2016)$.

\section{Metodologia}

Com o software Google Earth Pro identificou-se, ao longo do canal principal, os setores de interesse, ou seja, os que apresentavam barras e/ou ilhas. O índice de entrelaçamento $(\mathrm{Br})$ leva em consideração o comprimento do setor $(\mathrm{Cr})$ onde visivelmente existem barras e ilhas e o somatório de seus respectivos comprimentos $(\mathrm{Cb})$, medidos paralelamente ao sentido do fluxo. São incluídas as barras e ilhas que tenham comprimento superior ao dobro de sua largura e que estejam emersas. As barras submersas não são levadas em conta (Brice, 1964). Para padronizar a análise, definiu-se um comprimento padrão (Cr) de $1,5 \mathrm{~km}$.

$$
\mathrm{Br}=2 *\left(\sum \mathrm{Cb}\right) / \mathrm{Cr}
$$

Para o cálculo da sinuosidade do trecho, também recomendado por Islam (2011), utilizou-se o parâmetro de Fried e Sinha (1993) que definem a sinuosidade $(P)$ como sendo a razão entre comprimento do trecho medido ao meio do canal $(\mathrm{Cc})$ e a distância em linha reta entre o início e o fim do mesmo trecho $(\mathrm{Cv})$. Em canais entrelaçados, como neste caso, podese medir o comprimento ao meio do canal mais largo. Cabe ressaltar que o tipo de carga sedimentar é um fator de extrema importância no controle da sinuosidade de um canal (CUNHA, 2009).

$$
P=\mathrm{Cc} / \mathrm{Cv}
$$

Como as imagens mostram apenas o estado momentâneo da paisagem, preferiu-se as que possuíam menores amplitudes temporais, sem cobertura de nuvens. Optou-se por imagens de 2016 e 2015 dos meses de novembro e dezembro, período de estiagem, como sugerido por 
Saker et al (2014), para uniformizar e validar as medições de intensidade de entrelaçamento e sinuosidade.

Tavares et al (2009) calcularam a declividade ou gradiente (S) pela diferença de altitude em um trecho do canal $(\Delta \mathrm{h})$ em relação ao comprimento do trecho $(\mathrm{Cv})$. A declividade pode ser obtida pela seguinte equação:

\section{$\mathrm{S}=\Delta \mathrm{h} / \mathrm{Cv}$}

Em áreas de escarpa de falhas tectônicas e de piemonte, torna-se muito importante medir esta última variável (BIGARELLA et al, 2003).

Segundo Egozi \& Ashmore (2008) ainda existe muita incerteza envolvendo as correlações estatísticas relacionadas às variáveis morfométricas dos rios entrelaçados. A aplicação da morfometria permitiu a verificação da correlação entre as variáveis através do teste estatístico de Pearson ( $\rho$ ) que varia de -1 a 1 e mede o grau de dependência entre duas variáveis e verifica se a relação é positiva ou negativa (GUIMARÃES, 2017).

\section{RESULTADOS E DISCUSSÕES}

No que se refere a intensidade de entrelaçamento (Figuras 1, 3 e 4), pode-se constatar que a concentração dos valores está no intervalo entre as classes de 0,77 a 1,27, representando $40 \%$ dos resultados da mensuração desta variável. Apenas $4 \%$ das medidas de entrelaçamento estão locadas no intervalo de 2,28 a 2,79. Avaliou-se que $32 \%$ dos valores medidos se concentram na classe 0,26 a 0,77. A maior intensidade de entrelaçamento (Figura 5) foi medida no alto Mundaú, com valor de 2,79, em São José da Laje (AL), na zona de influência de um tributário. Outro ponto que merece destaque é o entrelaçamento nas imediações de Rio Largo (AL), com valor de 2,24 (Figura 1), a jusante da ponte da AL-210 e a montante de uma pequena barragem hidrelétrica, a poucos quilômetros da foz (MARQUES et al, 2016).

A distribuição de frequência dos valores obtidos pela aplicação do índice de sinuosidade (Figuras 2, 3 e 4) apresenta concentração entre o intervalo de 1,00 a 1,36. Cerca de $80 \%$ das seções analisadas tem sinuosidade neste intervalo. O maior valor obtido foi de 1,59 (Figura 2). Resultados semelhantes, no que se refere a distribuição de frequência de sinuosidade, foram obtidos por Gauw (2007) em estudo no rio Assu, Rio Grande do Norte. Como o fluxo helicoidal tem dificuldade em se estabelecer nos canais entrelaçados, por conta das barras e ilhas que funcionam como barreiras, tendencialmente sua sinuosidade diminui, 
assim como a profundidade, ao passo de que sua largura e potência de transporte aumenta, como explicam Fried \& Sinha (1993) e também Stevaux \& Latrubesse (2017).

Figura 1 - Maior intensidade entrelaçamento registrada. Destaca-se a presença de obras de engenharia no canal fluvial, como a ponte que intercepta o fluxo. Está área fica a montande de uma pequena barragem hidrelétrica.

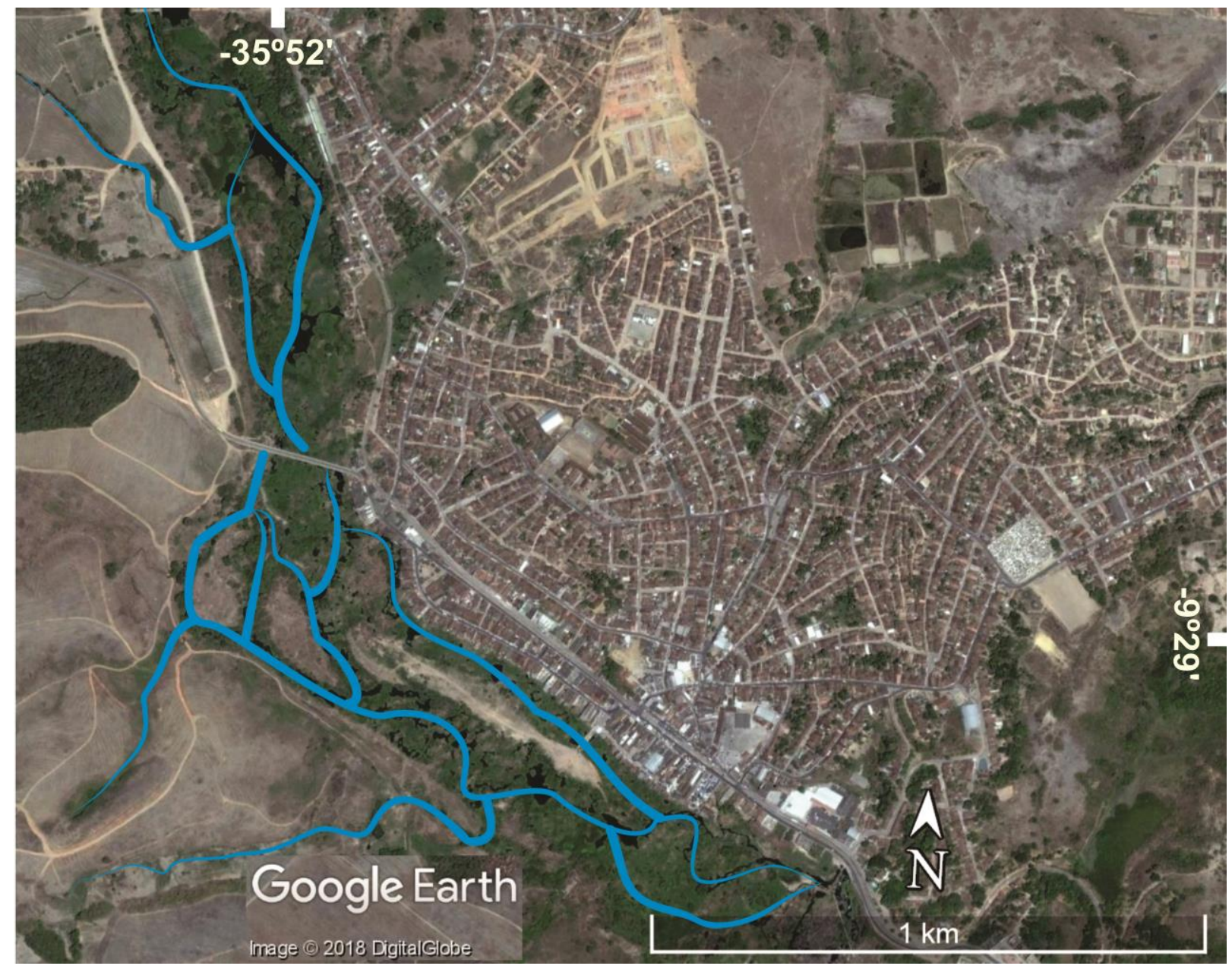

A declividade mantém valores baixos (Figura 4). Sua amplitude, diferença entre a maior e a menor declividade, foi de $0,0140 \mathrm{~m} / \mathrm{m}$. Mais de um terço das medições concentramse entre $0,0007 \mathrm{~m} / \mathrm{m}$ e $0,0035 \mathrm{~m} / \mathrm{m}$, ou seja, baixa declividade do canal. Declividades relativamente maiores, $0,0091 \mathrm{~m} / \mathrm{m}$ até $0,0141 \mathrm{~m} / \mathrm{m}$, onde existe significativo incremento da energia potencial do fluxo, representam somente $16 \%$ das mensurações. 
Figura 2 - Setor entrelaçado no município de São José da Laje (AL). Índice de entrelaçamento 1,5 e maior sinuosidade registrada 1,59 .

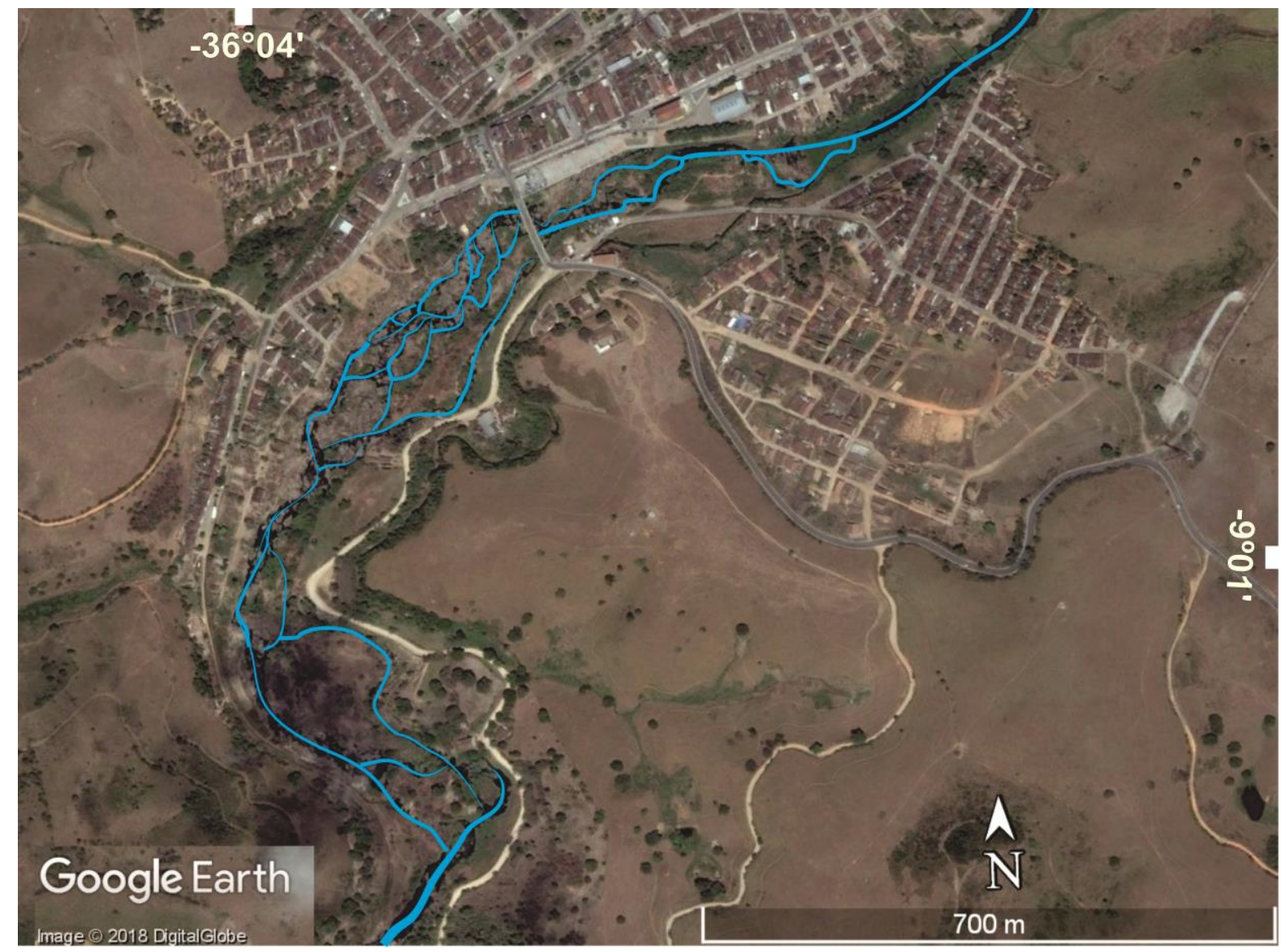

A declividade, somada a outros fatores, como o calibre e o volume de sedimentos e a própria descarga, interfere decisivamente nos processos de agradação e degradação dentro do canal fluvial (CHORLEY apud BRIERLEY \& FRYIRS, 2006). Como pode-se observar nas Figuras 3 e 4, existem três regiões onde se concentram trechos entrelaçados. A imagem 4 também demonstra que as variáveis têm correlação positiva entre si, mas apenas a declividade com relação a sinuosidade apresenta grau de correlação positiva moderada $(\rho=0,58)$.

A primeira região onde se concentra o entrelaçamento (de montante para jusante) é caracterizada pela presença de uma Zona de Cisalhamento Transcorrente Sinistral e por conjuntos de rochas de diversos graus de metamorfismo, com bandeamentos e foliações. Genericamente, essas características afetam significativamente o padrão de drenagem da área (MONTEIRO, 2015). 
Revista de Geografia (Recife) V. 35, No. 4 (especial XII SINAGEO), 2018

Figura 3 - Setores fluviais entrelaçados identificados da BHM. Notar que há no mínimo três regiões de concentração de trechos com padrão entrelaçado.
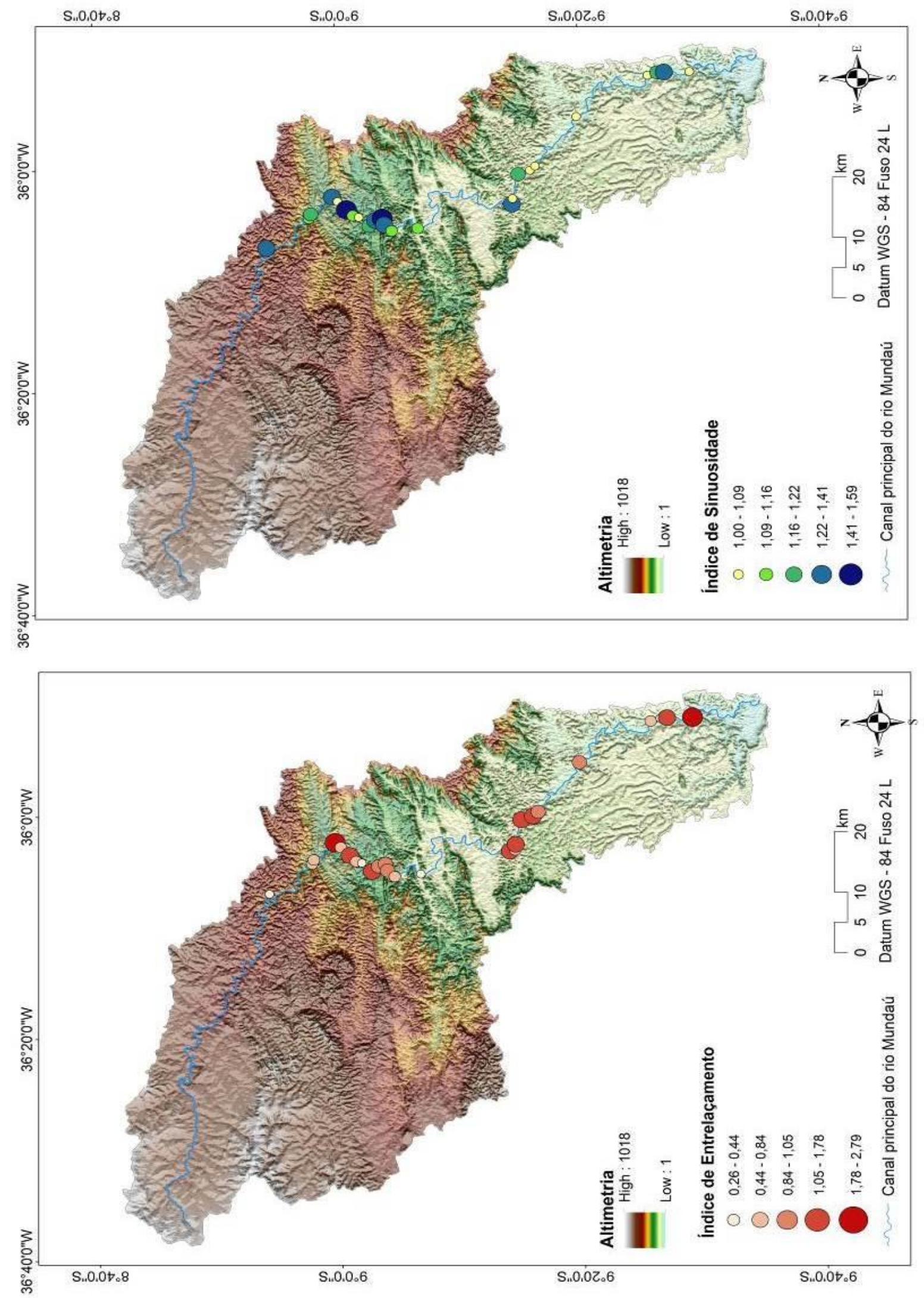
A cobertura vegetal é praticamente inexistente, tendo sido quase que totalmente substituída por cana-de-açúcar e pastagem, a precipitação anual total média acumulada chega a $1100 \mathrm{~mm}$. Geomorfologicamente, está inserida na unidade das colinas e morros dissecados que cobre $1565,7 \mathrm{~km}^{2}$ da área da bacia, com predomínio de relevo fortemente ondulado de acordo com o estudo de Gomes et al (2016).

Figura 4 - Índice de entrelaçamento, sinuosidade e declividade ao longo do canal principal da BHM. A sinuosidade e a declividade têm correlação positiva moderada $(\rho=0,58)$.

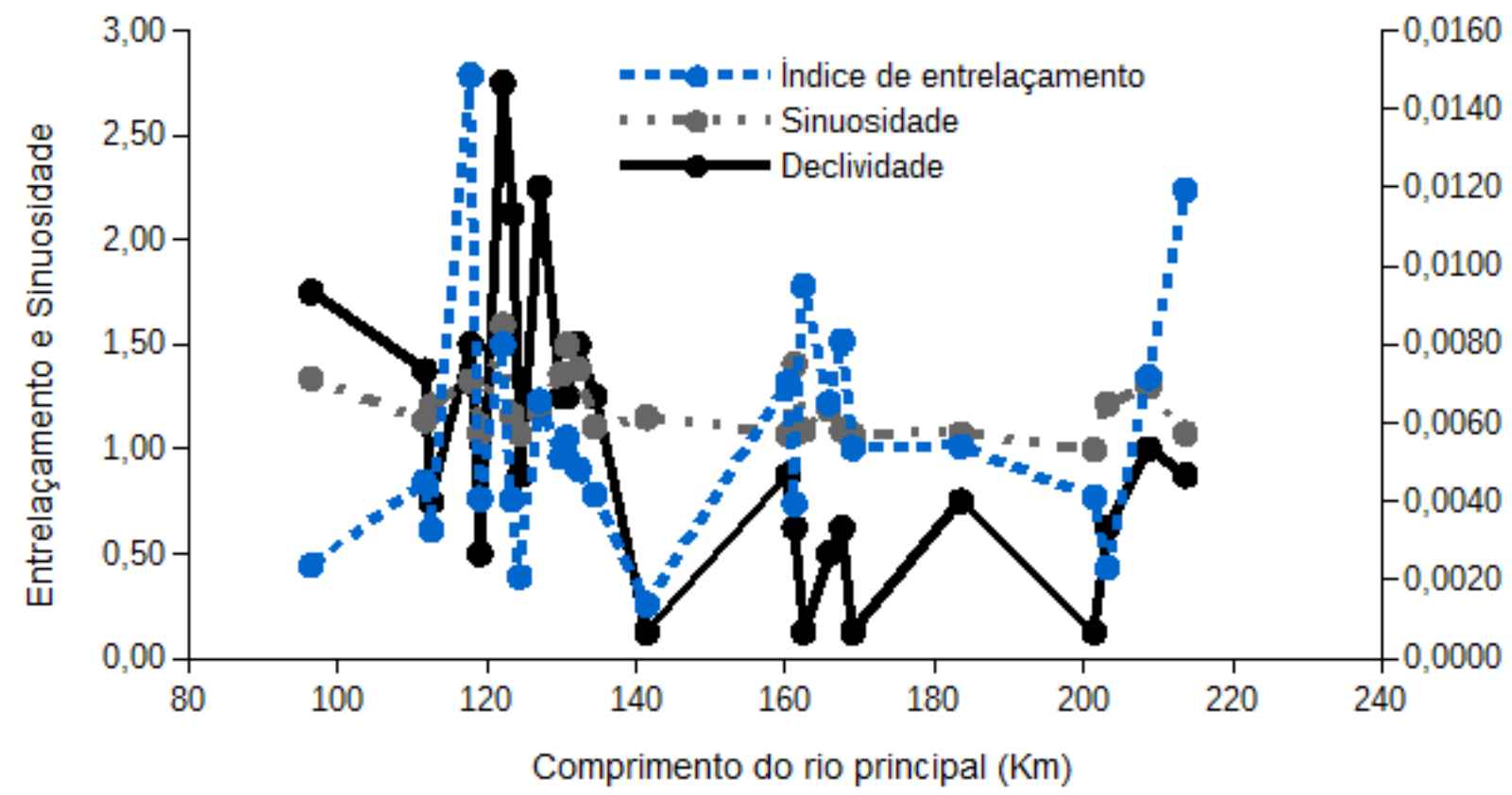

Seguindo a jusante, o entrelaçamento se concentra novamente, em um outro contexto geomorfológico. Ainda segundo a classificação geomorfológica da bacia proposta por Gomes et al (2016), dessa vez a concentração está na unidade das serras e das superfícies retrabalhadas, com sedimentos inconsolidados da Formação Barreiras e de complexos graníticos. É abundante nesta unidade as colinas de formato abaulado e cristas lineares. Esta unidade também possui alto grau de ondulação, sendo descrita como fortemente ondulada. A precipitação média anual é de $900 \mathrm{~mm}$, com vastas áreas destinadas a atividades de pastoreio e agricultura.

O último setor onde se concentram os trechos entrelaçados está a poucos quilômetros da desembocadura do rio Mundaú. Novamente encontra-se na área de concentração rochas metamórficas, como o granulito e o kingizito, que fazem parte do Complexo Nicolau/Campo Grande e uma Zona de Cisalhamento Extensional a jusante, ladeada por sedimentos da formação Barreiras, intercalados por siltitos e argilitos (MASCARENHAS; BELTRÃO; 
JUNIOR, 2005). Além disso, esta área é sublinhada por Gomes et al (2016) por alocar abundantes depósitos quartzoarenosos e terraços fluviais.

Como o meandramento, as causas que levam ao padrão entrelaçado ainda não são totalmente compreendidas. Entretanto, algumas considerações podem ser feitas.

Acredita-se que o entrelaçamento é uma resposta do canal em face ao aumento do suprimento de sedimentos e sua falta de capacidade de transporte. Nessa perspectiva, o entrelaçamento é uma retroalimentação positiva do sistema, uma maneira do rio transportar sua carga de sedimentos com a energia que possui. Quando este padrão se estabelece existe uma tendência a ser mantido, com pequenos ajustes ocasionais ou até com propagação a jusante. Em alguns setores esta alta carga de sedimentos está diretamente relacionada à entrada de um tributário, como verificado na figura 5.

Figura 5 - Entrelaçamento influenciado pela contribuição das águas de um afluente do rio Mundaú. Índice de entrelaçamento 2,79 e sinuosidade 1,33.

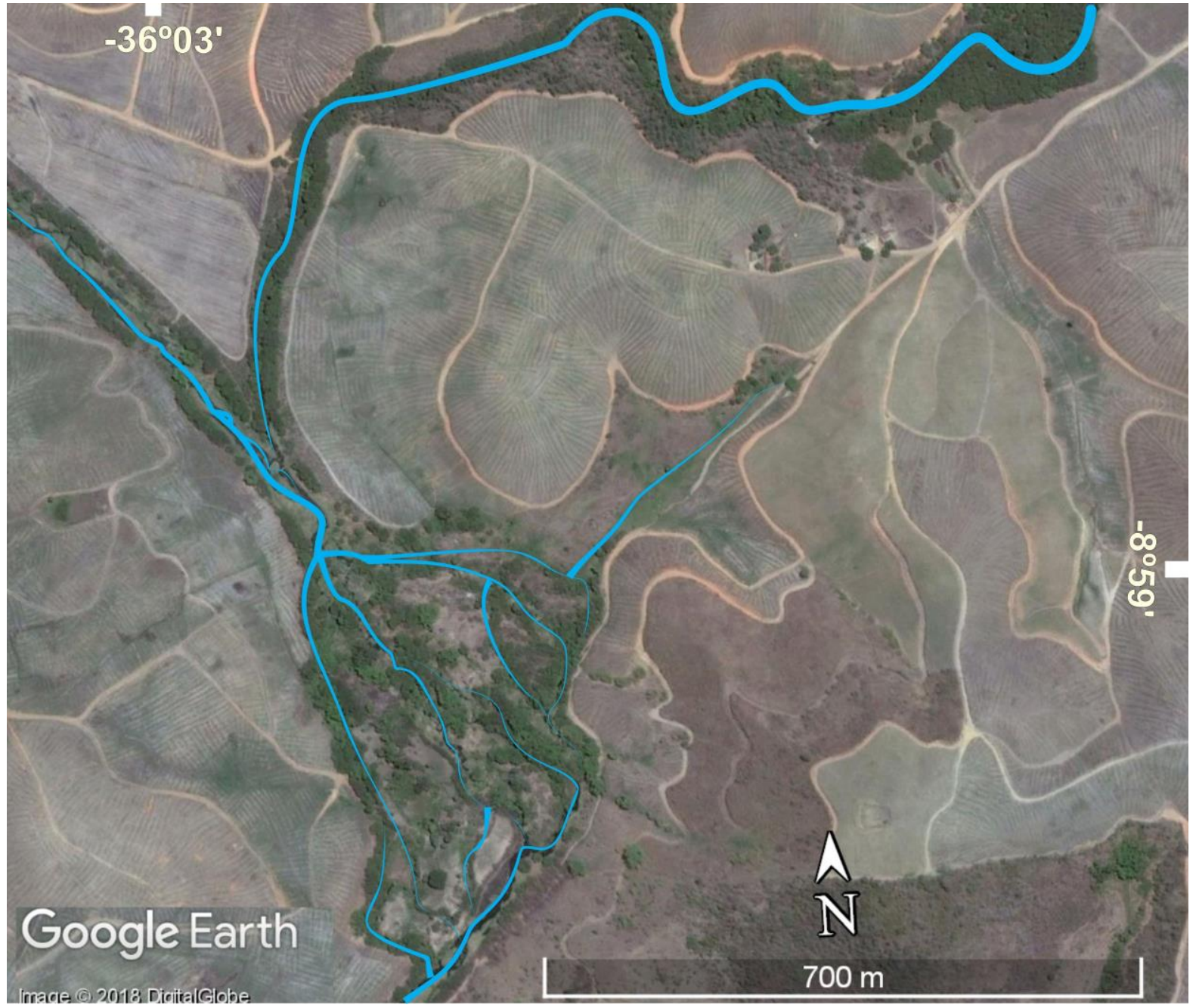


De modo geral, os grandes sistemas fluviais entrelaçados, como o rio Copper, nos Estados Unidos, são raros na natureza. Prevalece, como no caso estudado, entrelaçamentos de pequena escala, em trechos confinados de baixa vazão e elevado aporte de sedimentos (STEVAUX e LATRUBESSE op. cit. p.181).

\section{CONSIDERAÇÕES FINAIS}

Estudos como este mostram-se fundamentais, sobretudo para as pesquisas mais abrangentes sobre a morfologia e dinâmica dos rios tropicais do Nordeste. Entretanto, como já ressaltado, como a intensidade de entrelaçamento é muito sensível as variações do nível de água no rio, faz-se necessário o monitoramento multitemporal desta variável. Os estudos que enfocam a quantificação do entrelaçamento geralmente são desenvolvidos em rios de leito aluvial. Contudo, em vários dos trechos abarcados por esta pesquisa, o rio Mundaú apresenta leito misto, ou seja, rochoso com delgada cobertura sedimentar. Por isso, a rugosidade do leito é um fator de grande importância e que deve ser levado em consideração nos estudos morfogenéticos associados ao padrão entrelaçado no rio Mundaú. É a partir do leito que formas características deste padrão, tais como as barras, evoluem.

Além disso, a distribuição espacial do entrelaçamento obedece, como apontado por outros autores, certas influências. É o caso dos trechos nas proximidades das confluências, naqueles impactados por obras de engenharia, como a montante de barragens e a jusante de pontes e também aqueles que são notadamente influenciados pela geologia/geomorfologia e uso do solo na região. No mais, o rio Mundaú desenvolve entrelaçamento descontínuo, com declividade reduzida, sinuosidade baixa e igualmente baixa magnitude do índice de entrelaçamento.

\section{REFERÊNCIAS}

BRICE, J. C. Channel patterns and terraces of the Loup Rivers in Nebraska. U.S. Geological Survey Professional Paper, Washington, 1964.

BIGARELLA, J. J. Estrutura e origem das paisagens tropicais e subtropicais. Florianópolis: Ed. UFSC, 2003.

BRIERLEY, G. J.; FRYIRS, K. A. Geomorphology and river management: applications of the river styles framework. Blackwell Publishing, 2006. 
CUNHA, S. B. Geomorfologia fluvial. In: CUNHA, S. B.; GUERRA, A. J. T. Geomorfologia: exercícios, técnicas e aplicações. Rio de Janeiro: Bertrand Brasil, 2009.

CHRISTOFOLETTI, A. Geomorfologia. São Paulo: Edgard Blucher, 1980.

CHRISTOFOLETTI, A. Geomorfologia fluvial. São Paulo: Edgard Blucher, 1981.

EGOZI, R.; ASHMORE, P. Defining and measuring braiding intensity. Earth Surface Process and Landforms, v. 33, p.2121-2138, 2008.

FRIEND, P. F.; SINHA, R. Braiding and meandering parameters. Geological Society, London, Special Publications, v. 75, n. 1, p. 105-111, 1993.

GAUW, D. S. Estudo integrado de análogo a reservatórios petrolíferos fluviais: caracterização, parametrização e modelagem tridimensional de depósitos recentes do rio Assu (Rio Grande do Norte/Brasil). 2017. 74 p. Dissertação (mestrado em Geodinâmica e Geofísica) - UFRN, 2007.

GOMES, D. D. M. et al. Mapeamento e caracterização dos sistemas ambientais da bacia hidrográfica do Rio Mundaú - PE/AL. Caderno de Geografia, v.26, n.2, 2016.

GUIMARÃES, P. R. B. Análise de Correlação e medidas de associação. Disponível em: <goo.gl/Vtvg CG>. Acessado em 01 de novembro, 2017.

ISLAM, N. A. Y. Changing trends of channel pattern of the Ganges-Padma river. International Journal of Geomatics and Geosciences, v.2, n.2, 2011.

LEOPOLD, L. B.; WOLMAN, M. G. River channel patterns: braided, meandering and straight. U.S. Geological Survey Professional Paper, Washington, 1957.

LATRUBESSE, E.; STEVAUX, J. C.; SINHA, R. Grandes sistemas fluviais tropicais: uma visão geral. Revista Brasileira de Geomorfologia, Uberlândia, MG, v. 4, n.1, p. 1-18, 2005.

MAIA, R. P.; BEZERRA, F. H. Neotectônica, geomorfologia e sistemas fluviais: uma análise preliminar do contexto nordestino. Revista Brasileira de Geomorfologia, Uberlândia, MG, v. 12, n.3, p. 37-46, 2011.

MONTEIRO, K. A. Análise geomorfológica da Escarpa Oriental da Borborema a partir da aplicação de métodos morfométricos e análises estruturais. 2015. 222 p. Tese de doutorado (Programa de pós-graduação em Geografia UFPE) - Recife, 2015.

MONTE, B. E. O. et al. Modelagem hidrológica e hidráulica aplicada ao mapeamento de áreas inundáveis. Revista Brasileira de Recurso Hídricos, Porto Alegre, v.21, n.1, 2016.

MARQUES, J. W. F. et al. Determinação de parâmetros hidrológicos, morfométricos e problemas ambientais se em setor urbano da Bacia Hidrográfica do Rio Mundaú - município de Rio Largo. In: I Workshop de Geoarqueologia e Geomorfologia do Nordeste. Recife: GEQUA. Anais... 2016. p.49-55. 
MASCARENHAS, J. C.; BELTRÃO, B. A.; JUNIOR, L. C. S. Projeto cadastro de fontes de abastecimento por água subterrânea: diagnóstico do município de Rio Largo. Recife: CPRM/PRODEEM, 2005.

STEVAUX, J. C.; LATRUBESSE, E. M. Geomorfologia fluvial. São Paulo: Oficina de Textos, 2017.

SMITH, G. H. S. Braided rivers: process, deposits, ecology and management. Blackwell, 2006.

SARKER, M. H. et al. Morpho-dynamics of the Brahmaputra-Jamuna River, Bangladesh. Geomorphology, 2014.

TAVARES, B. A. C.; MIRANDA, C. S.; CORRÊA, A. C. B. Contribuição do estudo de padrões de canais para a elucidação da gênese da paisagem geomorfológica do Gráben do Cariatá, Paraíba. In: XII Congresso da Associação Brasileira de Estudos do Quaternário. La Plata. Anais... 2009. p.174-180. 